\title{
Racial disparities in COVID-19 impacts in Michigan, USA
}

\author{
Kaston D. Anderson-Carpenter • Zachary P. Neal
}

\begin{abstract}
Racial disparities have been observed in the impacts of COVID-19 in the United States. In this paper, we used a representative sample of adults in Michigan to examine differences in COVID-19 impacts on Blacks and Whites in four domains: direct, perceived, political, and behavioral. We found that in the initial wave of the outbreak in May 2020, Blacks experienced more severe direct impacts: they were more likely to be diagnosed or know someone who was diagnosed, and more likely to lose their job compared to Whites. Additionally, Blacks differed significantly from Whites in their assessment of COVID-19's threat to public health and the economy, the adequacy of government responses to COVID-19, and the appropriateness of behavioral changes to mitigate COVID-19's spread. Although in many cases these views of COVID-19 were also associated with political ideology, this association was significantly stronger for Whites than Blacks. Continued investigation of racial disparities in COVID-19's impact is necessary, however these preliminary findings of a race-by-ideology interaction are important because they suggest some racial disparities are restricted to conservatives, while more liberal Whites and Blacks exhibit few differences.
\end{abstract}

Keywords COVID-19 · SARS-CoV-2 · political ideology $\cdot$ racial disparities $\cdot$ public health

Kaston D. Anderson-Carpenter

Psychology Department

Michigan State University

316 Physics Rd.

East Lansing, MI 48824

Tel.: +1517-432-0686

E-mail: kaston@msu.edu

Zachary P. Neal

Psychology Department

Michigan State University

\section{Introduction}

Since the first confirmed case of the novel coronavirus (COVID-19) was reported in the United States on January 22, 2020, there has been an dramatic increase in morbidity and mortality rates due to the virus. Multiple studies of emerging national and local data suggests that communities of color are disparately affected by COVID-19, thus exacerbating existing health disparities [e.g., 1, 24, 19, 29, 2, 28]. In the state of Michigan, for example, Blacks comprise approximately $14.1 \%$ of the population yet make up more than $35 \%$ of deaths as of 5 November 2020 [22].

Although influencing factors of disproportionate rates among Blacks remain largely unknown, the existing literature cites several potential contributors. It is now known that individuals with compromised immune systems or pre-existing health conditions are more susceptible to acquiring COVID-19, and Blacks experience greater prevalence of certain health conditions such as Type 2 diabetes, hypertension, and asthma. Additionally, social determinants of health have been shown to play a major role in health outcomes. For example, socioeconomic status, education, and access to care have been cited as explanatory factors in both physical and mental health in various populations. In Michigan, such determinants contribute to greater disparities in health outcomes for Black residents. As more data become available, estimates of and explanations for differences in COVID-19 prevalence and impacts will improve. However, to date few studies of COVID-related racial disparities have considered the potential intersectional role of political ideology.

In response to the recent call to action [18], and seeking to explore the ways that race and politics may intersect to generate racial disparities, in this paper 
we examine the associations of race, political ideology, and their interaction with several direct and indirect COVID outcomes during the peak of the pandemic's first wave in Michigan. As expected based on prior studies, we find evidence of racial disparities in these outcomes between Black and White respondents. In addition, we observe that although several outcomes are also associated with political ideology, this association tends to be significantly stronger for Whites than Blacks. That is, we observe that although COVID and its impacts have become heavily politicized, there are racial disparities in the extent of its politicization.

The remainder of the paper is organized in four sections. In the background section we briefly review past research on racial disparities in COVID-19 and similar pandemic events. In the methods section, we describe the State of the State Survey of Michigan adults conducted in May 2020, which we use to measure a range of COVID outcomes including diagnosis, perceptions of severity, and adherence to behavioral changes. In the results section, we first report population estimates of these outcomes, then report our findings from a series of logistic and linear regressions estimating the association of race, political ideology, and their interaction on these COVID outcomes. In the discussion section, we conclude by discussing the implications of an ongoing and highly politicized public health crisis that has racially disparate impacts in multiple domains.

\section{Background}

Racial disparities in health outcomes have been long documented in the United States [5, 6, 9, 13, 30, 34]. With the growing implications of COVID-19 on American public health, the existing disparities may be further heightened. The emerging findings suggests that Blacks are at a greater risk of acquiring and dying from COVID-19 compared to their White peers, which may be exacerbated by prevailing disparities in economic stability and healthcare access $[23,4]$.

Since the first case of COVID-19 appeared in Washington State in February 2020, unemployment in the United States increased $217 \%$ by June 2020. During this period, Black Americans consistently experienced a greater unemployment rate, with June 2020 estimates of $15.4 \%$ unemployment compared to $10.1 \%$ unemployment for their White peers [32]. These recent findings are consistent with studies demonstrating that Blacks experience lower levels of economic stability and higher rates of unemployment compared to their White counterparts [12, 17, 27],

Recent empirical studies published in the Journal of Racial and Ethnic Health Disparities further demonstrate the disproportionately negative impact of COVID-19 on Blacks in the United States. For instance, hospitalization data from New York City suggest that Blacks are twice as likely to require COVID-related hospitalizations compared to their White peers [29], and Blacks were disproportionately represented in COVIDrelated mortality cases compared to Whites. Other work suggests that communities with greater concentrations of Blacks showed substantially more cases of COVID-19 [1, 2, 19] These findings may be partially explained by the fact that Blacks are more likely to present with comorbidities such as hypertension and Type 2 diabetes than their White counterparts, and are also disproportionately affected by stress and other social determinants of health such as unemployment and lack of adequate access to healthcare [28].

Differences in the perceived impacts of COVID-19 have yet to be fully explored in the United States. That said, news reports point to a potential difference in perceived susceptibility (i.e., subjective perception of the risk of acquiring COVID-19) and severity of the virus (i.e., feelings on, and perceptions of, the seriousness of acquiring COVID-19) on overall health. More specifically, there is some evidence of differential feelings of the seriousness of acquiring COVID-19. Media outlets have reported on "coronavirus parties" in the United States; In one state, it was reported that students attended such a party in an effort to acquire and/or transmit COVID-19 [15]. Additionally, some individuals in the US resist behavioral preventive measures such as staying at home and wearing face masks as an affront to freedom of expression; others who acquire the virus may refuse participation in contact tracing. These activities may be a byproduct of rising levels of health and economic anxiety. In a recent nationwide community sample, scholars have found that being under a stay-at-home order and perceived negative impacts of COVID-19 on daily life were independently associated with greater health anxiety and economic worry [31].

Some of the resistance in practicing preventive measures may be influenced by ideological orientation. Empirical evidence suggests that conservatism is correlated with engagement in more conspiracy-related information and media exaggeration. For example, recent work has shown that individuals who identified as Republicans and conservatives perceived a lower COVID-19 related vulnerability compared to Democrats and liberals [8]. These results mirror prior work that suggests political ideology is associated with a fear of threat and loss [16].

The fact that conservatism was associated with lower threat perception of COVID-19 may be due, in part, to the impact of prevailing political leadership 
and partisan media [8]. On the one hand, liberal-leaning media outlets have attributed the current downplay of COVID-19 related vulnerability to the current presidential administration and the Republican party [11]. On the other hand, conservative-leaning outlets have argued that their liberal counterparts have been using the current pandemic as a tool to discredit the Republican Party and current Administration [14]. Another potential mechanism can be found in the motivated social cognition model of conservatism [16]. The model suggests that individuals may embrace conservatism in part because it reduces anxiety and fear, especially in the face of crisis. This assertion has been supported by empirical research demonstrating significantly more conservative political attitudes before and after the September 11, 2001 terrorist attacks [25]. Thus, a crisis such as the COVID-19 pandemic, along with prevailing leadership and partisan media, may prompt some individuals to adopt political conservatism as a psychological coping mechanism.

In many ways, Michigan is a microcosm of the United States. The Black population in Michigan is slightly larger than that of the United States (13.4\% compared to 13.4\%) [33]. However, similar distributions between Michigan and the United States exist across gender, age, and education. Although 2019 Census estimates suggest a lower poverty rate $(11.8 \%)$ compared to the national average (14.1\%), approximately $10.0 \%$ of Michiganders do not have health insurance compared to the national average of $6.4 \%$ [33]. Politically, Michigan is often considered a "battleground" state given its ideological diversity $[21,10]$. In the 2016 presidential election, for example, Michigan was considered a crucial state for candidates to win electoral votes. As such, understanding racial disparities of COVID-19 and their associated factors may have public health, economic, and political implications for years to come.

Because the COVID-19 pandemic is ongoing, little is yet known about the potential differences in its direct, perceived, ideological, and behavioral impacts on Blacks versus White Americans. Furthermore, although there is some evidence suggesting ideological differences exist regarding COVID-19 threat perception in Michigan [7], it remains unknown whether or how those differences may intersect with potential racial disparities. In response to the recent call to action to identify and address racial and ethnic disparities related to COVID19 [18], we examined these disparities in a sample of Michigan adults. To that end, we hypothesized that: (1) Blacks in Michigan will experience significantly different direct, perceived, ideological, and behavioral effects of COVID-19 compared to their White counterparts; (2) those holding a liberal political ideology will experi- ence significantly different direct, perceived, ideological, and behavioral effects of COVID-19 compared to their ideologically conservative counterparts, and (3) political ideology will significantly moderate the relationship between race and COVID-19 outcomes.

\section{Methods}

\section{Data}

We used data from the State of the State Survey (SOSS), which was collected by YouGov for the Institute For Public Policy and Social Research (IPPSR) at Michigan State University between May 8 and 25, 2020. The survey initially included 1086 respondents, which were matched on gender, age, race, and education to a sampling frame constructed from the 2016 American Community Survey, to yield a final representative sample of 1000 Michigan adults. The timing of the data collection is significant for two reasons. First, it occurred while Michigan residents were under a stayat-home order, and at a time that Michigan had among the largest number of confirmed COVID-19 cases and deaths (57,601 and 5,479, respectively, by May 25$)$. Second, data collection ended on the day that George Floyd was killed by then-officer Derek Chauvin in Minneapolis, which sparked widespread protests against police brutality, particularly toward Blacks. Thus, the data record Michigan residents' self-reported COVID-19 experiences at the (initial) peak of the outbreak, but before these experiences could have been impacted by the protests. We focus on the subsample of respondents identifying as either Black or White, and were not missing data any of the variables described below $(\mathrm{N}=798)$.

\section{Outcomes: COVID-19 Impacts}

We examined four types of impacts that COVID-19 has had on Michigan residents: direct, perceived, political, and behavioral.

We examined two direct impacts of COVID-19. First, the variable diagnosed was a binary indicator variable coded 1 for respondents who had been diagnosed or personally knows someone who has been diagnosed with COVID-19, and otherwise is 0. Second, the variable unemployed was a binary indicator variable coded 1 for respondents who were working immediately prior to the outbreak, but are no longer working, and otherwise is 0 . Analyses examining this variable were restricted to the 446 respondents that were employed prior the outbreak. 
We examined three perceived impacts of COVID-19. The variables economy and health measured the respondent's perception of the threat of COVID-19 to the U.S. economy and health, respectively. Both threat variables were measured on a 3-point scale ranging from 'not a threat' (1) to 'a major threat' (3). The variable seriousness measured the respondent's perception of the seriousness of COVID-19 on a 3 -point scale ranging from 'generally exaggerated' (1) to 'generally underestimated' (3).

We examined five political impacts of COVID-19. The variables President, Federal, Governor, State, and Local each measured the respondent's rating of the respective elected official's of level of government's handling of COVID-19. These variables were measured on a 4-point scale ranging from 'poor' (1) to 'excellent' (4).

Finally, we examined two behavioral impacts of COVID-19. The variable mask measured the frequency with which the respondent wears a mask when going out, and ranges from 'never' (1) to 'always' (4). The variable stay-at-home measured the respondent's belief in the appropriate response to Michigan Governor Gretchen Whitmer's executive stay-at-home order, and ranges from 'non-compliance' (1) to 'compliance' (3).

\section{Predictors: Race and Political Ideology}

In these analyses, we focused on two potential predictors of variation on these outcomes: race and ideology. The variable Black was a binary indicator variable coded 1 for respondents who identified as Black (alone, or in combination with any other race), and coded 0 for respondents who identified as White alone. The variable ideology was measured on a 7 point scale that ranged from 'very conservative' (1) to 'very liberal' (7).

\section{Control Variables}

All models controlled for age in years (and agesquared), sex, and education. Sex was measured using a binary indicator variable coded 0 for males and 1 for females. Education was measured on a 7 -point scale that ranged from 0 for no high school, to 6 for graduate degree.

\section{Analytic Plan}

To describe the adult population of Michigan at the peak of the first wave of the COVID-19 outbreak, we estimated population means for all variables using the complete $\mathrm{N}=1000$ sample. These population means were estimated using the survey package for $\mathrm{R}$ [20] to incorporate sampling weights that ensure representiveness by sex, age, race, education, and 2016 presidential vote choice.

To test for disparities in COVID-19 impacts by race, political ideology, and their interaction, we estimated a series of logistic (for the two binary direct impacts) and linear (for all other impacts) regressions. We did not use sampling weights for these analyses because the sampling weights are a function of covariates already included in the models [35]. All continuous independent variables included in these models were meancentered prior to analysis and prior to the construction of squared and interaction terms.

Replication code for these analyses is available from the Open Science Framework at https://bit.ly/351zIGh. The data used in these analyses is available from the Institute For Public Policy and Social Research (IPPSR) at Michigan State University at http://ippsr.msu.edu.

\section{Results}

\section{Population and Sample Characteristics}

Table 1 reports the estimated population means and computed sample means for each variable included in the analysis. These values highlight that the unweighted sample closely matched the estimated characteristics of Michigan's adult population.

Approximately one-third of Michigan adults had been directly impacted by the COVID-19 outbreak by late May, having lost their job (33\%), or having been diagnosed or known someone who was diagnosed (31\%), or both. Nonetheless, they viewed the outbreak as a more serious threat to the U.S. economy $(\hat{\mu}=2.87)$ than to U.S. health $(\hat{\mu}=2.56)$, and reported that its seriousness was somewhat overestimated $(\hat{\mu}=1.87)$. They viewed the government response to COVID-19 as only fair $(\hat{\mu}=2.09-2.54)$, with more negative impressions of the response at the federal level than at the state or local levels. This is reflected in their general willingness to comply with state and local orders to wear a mask $(\hat{\mu}=3.03)$ and to stay at home $(\hat{\mu}=2.37)$.

\section{COVID-19 Impact Disparities by Race and Ideology}

Table 2 reports the estimates from a series of logistic and linear regressions examining disparities in COVID19 impacts by race and political ideology. In this table, each row reports a separate model predicting a different COVID-19 impact, while each column reports 
Table 1 Population and sample characteristics.

\begin{tabular}{|c|c|c|c|c|c|c|}
\hline \multirow[b]{2}{*}{ Continuous Variables } & \multicolumn{3}{|c|}{ Sample $(\mathrm{N}=789)$} & \multirow[b]{2}{*}{ Max } & \multicolumn{2}{|c|}{ Population Estimate $^{\alpha}$} \\
\hline & Mean & $\mathrm{SD}$ & Min & & Mean & $\mathrm{SE}$ \\
\hline Age & 53.70 & 16.82 & 19 & 95 & 49.85 & 0.80 \\
\hline Education & 2.87 & 1.81 & 0 & 6 & 2.46 & 0.08 \\
\hline Ideology & 4.20 & 2.07 & 1 & 7 & 4.03 & 0.09 \\
\hline Economy & 2.89 & 0.36 & 1 & 3 & 2.87 & 0.02 \\
\hline Health & 2.61 & 0.61 & 1 & 3 & 2.56 & 0.03 \\
\hline Seriousness & 1.95 & 0.74 & 1 & 3 & 1.87 & 0.03 \\
\hline President & 1.98 & 1.25 & 1 & 4 & 2.15 & 0.05 \\
\hline Federal & 2.00 & 0.93 & 1 & 4 & 2.09 & 0.04 \\
\hline Governor & 2.66 & 1.20 & 1 & 4 & 2.47 & 0.05 \\
\hline Michigan & 2.31 & 0.91 & 1 & 4 & 2.27 & 0.04 \\
\hline Local & 2.64 & 0.84 & 1 & 4 & 2.54 & 0.03 \\
\hline Mask & 3.14 & 0.97 & 1 & 4 & 3.03 & 0.04 \\
\hline Stay-at-home & 2.44 & 0.76 & 1 & 3 & 2.37 & 0.03 \\
\hline Categorical Variables & $\mathrm{N}$ & Percent & & & Percent & $\mathrm{SE}$ \\
\hline \multicolumn{7}{|l|}{ Sex } \\
\hline Male & 347 & 43.98 & & & 47.98 & 2.09 \\
\hline Female & 442 & 56.02 & & & 52.02 & 2.09 \\
\hline \multicolumn{7}{|l|}{ Race } \\
\hline White & 685 & 86.82 & & & 80.77 & 1.86 \\
\hline Black & 104 & 13.18 & & & 11.15 & 1.48 \\
\hline Other & 0 & 0 & & & 8.08 & 1.36 \\
\hline \multicolumn{7}{|l|}{ Diagnosed } \\
\hline Yes & 253 & 32.07 & & & 30.78 & 1.99 \\
\hline No & 536 & 67.93 & & & 69.22 & 1.99 \\
\hline \multicolumn{7}{|l|}{ Unemployed $^{b}$} \\
\hline Yes & 145 & 32.74 & & & 33.04 & 2.67 \\
\hline No & 301 & 67.49 & & & 66.96 & 2.67 \\
\hline
\end{tabular}

the estimated association of the three variables of interest on this impact. All models control for sex, age, age $^{2}$, and education. For clarity, estimated associated with control variables are not reported in the table, but are available in the online supplementary material at https://bit.ly/351zIGh.

We examined two direct impacts of COVID-19: diagnosis and job loss. Compared to White respondents, Black respondents were 3 times more likely to be diagnosed or personally know someone who was diagnosed with COVID-19 (p ; 0.01). Similarly, Black respondents were also more than twice as likely to have lost their job following the COVID-19 outbreak ( $p ; 0.01)$. These direct impacts had only weak and mixed associations with political ideology.

In contrast, both race and political ideology were consistently associated with perceived, political, and behavioral impacts of COVID-19. First, Black and White respondents had statistically significantly different perceptions of the threat and seriousness of COVID19. Compared to White respondents, Black respondents viewed it as less of a threat to the U.S. economy $(b=-0.1, p<0.01)$ and more of a threat to U.S. health $(b=0.19, p<0.01)$. Black respondents also viewed this threat as more serious $(b=0.29, p<0.01)$. Although more liberal respondents viewed the outbreak as a greater threat to U.S. health $(b=0.14, p<0.01))$ and as more serious $(b=0.19, p<0.01)$, the association with ideology was weaker for Black respondents $(b=-0.12$ and -0.16 , respectively; $p<0.01)$.

Second, Black and White respondents had statistically significanly different evaluations of government responses to the COVID-19 outbreak. Compared to White respondents, Black respondents viewed the President's response much more negatively $(b=-0.63, p<$ $0.01)$, and viewed state and local responses much more favorably (Governor: $b=0.71$; State: $b=0.53$; Local: $b=0.38 ; p<0.01)$. Approval of government responses was associated with political ideology in expected directions (e.g., more liberal respondents disapprove of federal-level responses, but approve of state and locallevel responses), however in the case of views about the president, governor, and state of Michigan, ideology played a much weaker role for Black respondents (President: $b=0.27, p<0.01$; Governor: $b=-0.24, p<0.01$; State: $b=-0.12, p<0.05)$. 
Table 2 COVID-19 impact disparities by race and ideology

\begin{tabular}{lllll}
\hline & & \multicolumn{3}{c}{ Independent Variable } \\
\cline { 4 - 5 } Impact $(\mathrm{DV})$ & Intercept & Black & Ideology & Interaction \\
\hline Direct $^{a}$ & & & & \\
Diagnosed & - & $3.07^{* *}$ & $1.15^{* *}$ & 0.85 \\
Unemployed $^{b}$ & - & $2.36^{* *}$ & 1.07 & 0.76 \\
& & & & \\
Perceived & & & & \\
Economy & $2.93^{* *}$ & $-0.10^{* *}$ & -0.00 & 0.01 \\
Health & $2.54^{* *}$ & $0.19^{* *}$ & $0.14^{* *}$ & $-0.12^{* *}$ \\
Seriousness & $1.87^{* *}$ & $0.29^{* *}$ & $0.19^{* *}$ & $-0.16^{* *}$ \\
& & & & \\
Political & & & & \\
President & $2.12^{* *}$ & $-0.63^{* *}$ & $-0.44^{* *}$ & $0.27^{* *}$ \\
Federal & $2.00^{* *}$ & -0.09 & $-0.18^{* *}$ & 0.06 \\
Governor & $2.48^{* *}$ & $0.71^{* *}$ & $0.38^{* *}$ & $-0.24^{* *}$ \\
State & $2.13^{* *}$ & $0.53^{* *}$ & $0.13^{* *}$ & $-0.12^{*}$ \\
Local & $2.53^{* *}$ & $0.38^{* *}$ & $0.09^{* *}$ & -0.07 \\
Behavioral & & & & \\
Mask & & & & \\
Stay-at-home & $2.86^{* *}$ & $0.48^{* *}$ & $0.16^{* *}$ & -0.07 \\
\hline
\end{tabular}

Rows represent separate models (DVs), and columns represent independent variable effects. All models control for sex, age, age $^{2}$, and education.

${ }^{a}$ Binary outcomes; reported values are odds ratios.

${ }^{b}$ Estimated on subsample of 446 that were employed pre-COVID

${ }^{* *} p<0.01,{ }^{*} p<0.05$

Finally, Black and White respondents' approval of COVID-19 transmission-mitigating behavioral changes differed significantly. Black respondents reported wearing a mask more often than White respondents $(b=$ $0.48, p<0.01$ ), and reported greater willingness to comply with stay-at home orders than White respondents ( $b=0.35, p<0.01)$. Again, these behaviors were associated with political ideology in expected ways, with more liberal respondents reporting more frequent mask wearing $(b=0.16, p<0.01)$ and more compliance with stay-at-home orders $(b=0.24, p<0.01)$. However, the ideological impact on stay-at-home compliance was significantly weaker among Black respondents $(b=-0.19, p<0.01)$.

Figure 1 illustrates the race-by-ideology interactions reported in Table 2. These plots show the estimated marginal means and associated 95\% confidence intervals for Black respondents in purple and White respondents in orange. The moderated effect can be interpreted in two ways. First, by viewing race's association with a COVID-19 impact as the main effect moderated by ideology, these results suggest that although Blacks and Whites differ, these differences occur primarily among conservative Blacks and Whites. For example, in their evaluation of the appropriateness of obeying the Michigan Governor's stay-at-home order, both liberal Blacks and Whites reported that full compliance was appropriate. In contrast, conservative
Blacks reported that full compliance was appropriate, while conservative Whites favored only reluctant compliance. Second, by viewing ideology's association with the a COVID-19 impact as the main effect moderated by race, these results suggest that ideology is associated with how individuals view COVID-19 impacts, but that this association is stronger for Whites than Blacks. For example, the slope relating ideology and evaluation of the stay-at-home order is steep for White respondents, but nearly flat for Black respondents.

\section{Discussion}

In this paper, we investigated differential impacts of COVID-19 on Black and White adults in Michigan. Black adults in Michigan are more likely to experience direct health and economic impacts compared to their White peers, but view COVID-19 more as a health problem than an economic problem. This perception may be due to greater prevalence of pre-existing conditions (e.g., hypertension, diabetes, asthma) that exacerbate its severity. Such pre-existing conditions are often attributed to social determinants of health, which have been shown to have significant deleterious effects on communities of color, and especially Black communities $[6,9,13,30,34]$. Our results are consistent with emerging trends suggesting that Black American adults are more directly impacted by COVID-19 than their White counterparts [23, 4, 1, 24, 19, 29, 2, 28]. Notably, some epidemiological data suggest that almost $90 \%$ of primarily Black communities reported COVID-19 related morbidity and almost 50\% mortality rates [23].

Despite, or perhaps because of, the differential health impacts, Black adults in Michigan were also more willing to change their behaviors to mitigate viral spread by wearing masks and staying at home compared to White adults. Other scholars have found similar results in various communities of color; Black adults have been found to have almost three-fold greater odds of endorsing higher levels of health practices to minimize their risk of COVID-19 infection and transmission compared to their White peers [3]. Although empirical investigations on racial and ethnic differences in COVID-19 related health behavior is limited, the existing evidence suggests that Black adults may be more likely to engage in such behavior due, at least in part, to the prevalence of pre-existing conditions and their associated social determinants of health.

In addition to observing racial disparities in COVID-19 impacts, we also observed anticipated differences associated with political ideology. Specifically, liberal adults in Michigan viewed COVID-19 as a greater 
Perceived
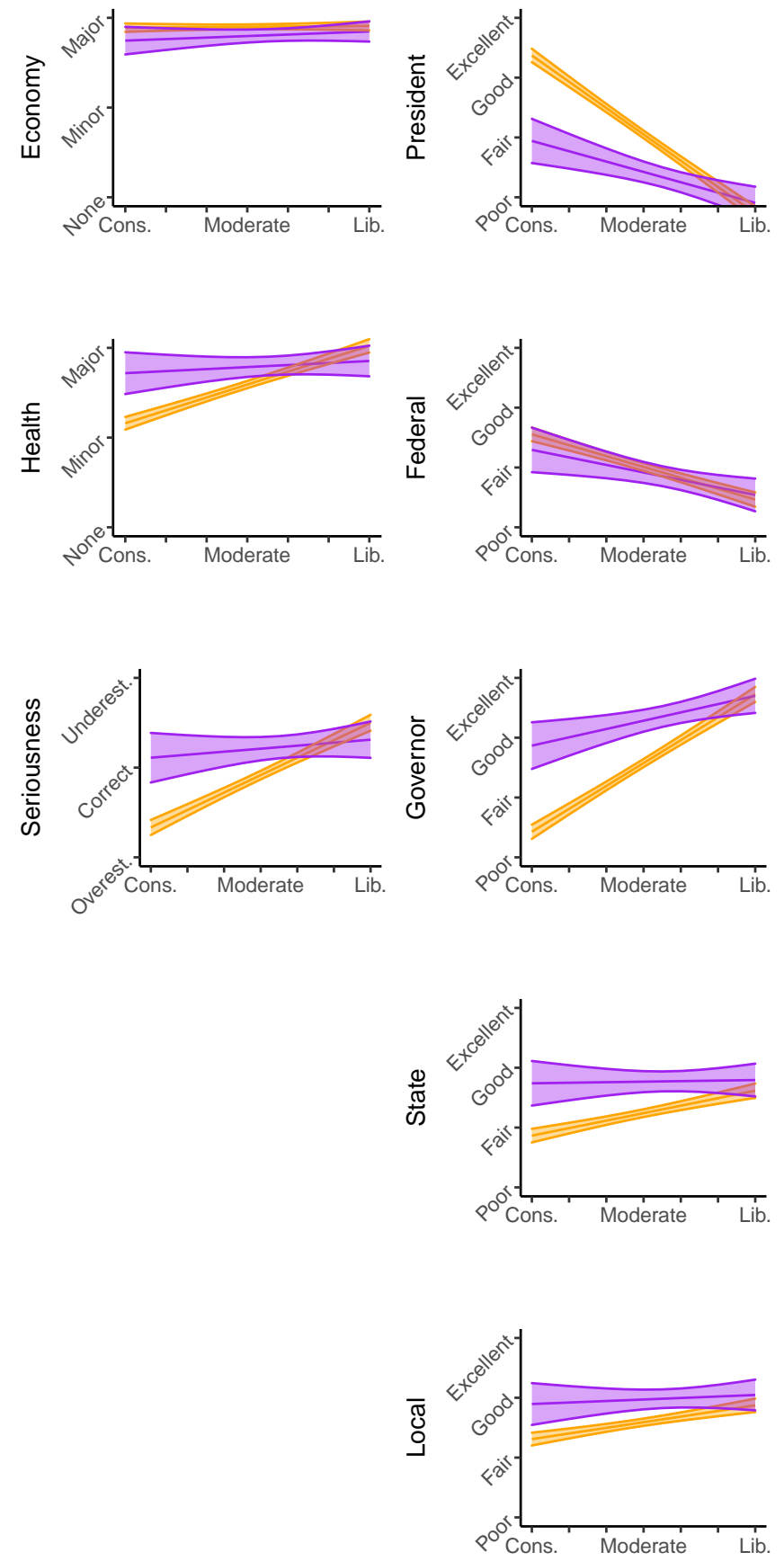

Political
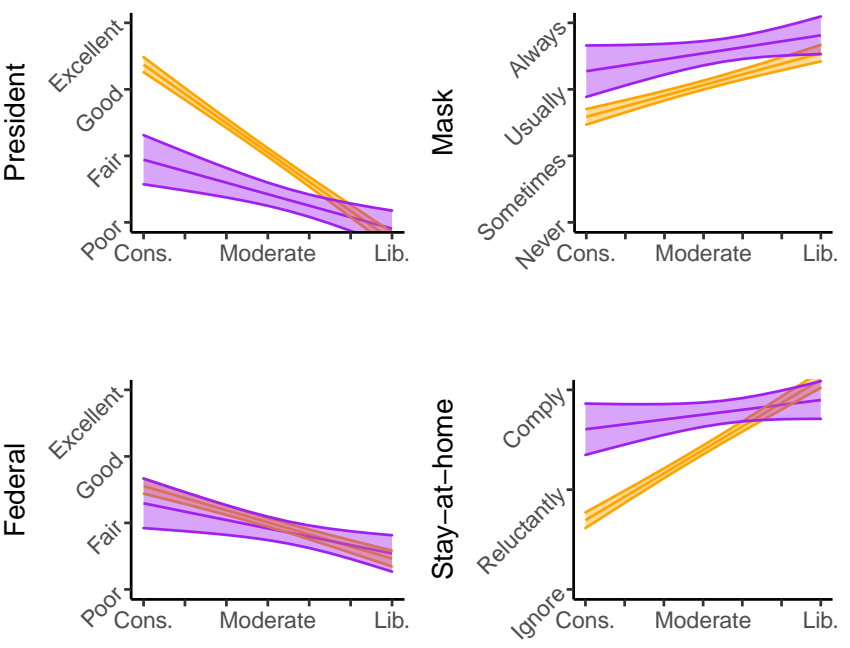

Behavioral

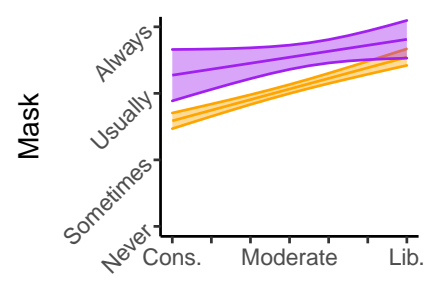


ferences on these dimensions that we observe between Blacks and Whites occur primarily among conservatives, while more liberal Blacks and Whites are similar. This finding of a race-by-ideology interaction is preliminary, but can guide future research on racial disparities not only related to COVID-19, but also to other health issues. Specifically, future research on racial health disparities should consider whether apparent differences between racial or ethnic groups depends on other contextual factors, such as political ideology. Considering the intersectional role of political ideology on racial health disparities may be even more important in the wake of highly-charged race-related political protests that have occurred during the COVID-19 pandemic but after these data were collected. This finding, if it can be replicated in other settings and for other health issues, may also have practical implications because it would imply that public health officials seeking to reduce disparities by delivering targeted services and messages must consider not only race, but also political ideology.

\section{Limitations and Future Directions}

This empirical study does not come without limitations, and the results should be interpreted with caution. First, due to the relatively small numbers of other racial and ethnic groups (e.g., Hispanic/Latinx, Asian, Native American) in Michigan, we were unable to fully examine the extent to which racial identity and political ideology affects perceptions of direct and indirect of COVID-19. Second, as self-reported survey data, there is the risk of response bias, particularly driven by fear and anxiety at the peak of the pandemic, that led respondents to provide more extreme responses. Third, as cross-sectional data concerning an ongoing public health crisis, we are unable to draw causal conclusions about the relationship between political ideology and perceptions of COVID-19 related impacts. Although trends toward political polarization in the United States are longstanding [26] and therefore individual political ideologies are relatively entrenched, it is also possible that the magnitude of COVID-19 impacts may yield changes in individuals' political ideology.

These limitations notwithstanding, this study is among the first to examine COVID-19 racial disparities in the context of differences in political ideology. As a demographically representative but politically diverse state, Michigan offers an opportunity to investigate potential intersections of race and ideology in COVID-19 outcomes, and thus to better understand the landscape within which public health interventions must be developed. In response to the recent call to action to address COVID-19 related racial disparities
[18], we observed expected racial disparities in two direct COVID-19 impacts [i.e., diagnosis and job loss; e.g., 1, 24, 19, 29, 2, 28] as well as racial differences in three more indirect types of COVID-19 impacts (i.e. threat assessment, government response approval, and behavior change adoption). However, the magnitude of racial differences in these indirect impacts was moderated by political ideology, such that liberal Whites and Blacks were similar, while conservative Whites and Blacks were different. These findings suggest that while public health officials attend to racial disparities in COVID-19 impacts, for example by targeting their messages and services to specific groups, these efforts must also consider the potential impact of individuals' political ideology.

Acknowledgements This work was supported in part by a Michigan Applied Public Policy Grant from the Institute for Public Policy Research at Michigan State University.

\section{Conflict of interest}

The authors declare that they have no conflict of interest.

\section{References}

1. Abedi V, Olulana O, Avula V, Chaudhary D, Khan A, Shahjouei S, Li J, Zand R (2020) Racial, economic, and health inequality and covid-19 infection in the united states. Journal of racial and ethnic health disparities pp 1-11

2. Akanbi MO, Rivera AS, Akanbi FO, Shoyinka A (2020) An ecologic study of disparities in covid-19 incidence and case fatality in oakland county, mi, usa, during a state-mandated shutdown. Journal of Racial and Ethnic Health Disparities pp 1-8

3. Alobuia WM, Dalva-Baird NP, Forrester JD, Bendavid E, Bhattacharya J, Kebebew E (2020) Racial disparities in knowledge, attitudes and practices related to covid-19 in the usa. Journal of Public Health

4. Anyane-Yeboa A, Sato T, Sakuraba A (2020) Racial disparities in covid-19 deaths reveal harsh truths about structural inequality in america. Journal of Internal Medicine

5. Bleser WK, Miranda PY, Jean-Jacques M (2016) Racial/ethnic disparities in influenza vaccination of chronically-ill us adults: The mediating role of perceived discrimination in healthcare. Medical care $54(6): 570$ 
6. Braveman P, Gottlieb L (2014) The social determinants of health: it's time to consider the causes of the causes. Public health reports 129(1_suppl2):1931

7. Bush D (2020) In michigan, political divides create two pandemic realities. PBS News Hour URL https ://www.pbs.org/newshour/politics/inmichigan-political-divides-create-twopandemic-realities

8. Calvillo DP, Ross BJ, Garcia RJ, Smelter TJ, Rutchick AM (2020) Political ideology predicts perceptions of the threat of covid-19 (and susceptibility to fake news about it). Social Psychological and Personality Science p 1948550620940539

9. Como DH, Stein Duker LI, Polido JC, Cermak SA (2019) The persistence of oral health disparities for african american children: a scoping review. International journal of environmental research and public health 16(5):710

10. Damore DF, Lang RE, Danielsen KA (2020) Blue Metros, Red States: The Shifting Urban-Rural Divide in America's Swing States. Brookings Institution Press

11. Drezner DW (2020) The unique incompetence of donald trump in a crisis. The Washington Post URL https://www.washingtonpost.com/ outlook/2020/03/09/unique-incompetencedonaldtrump-crisis/

12. Galea S, Abdalla SM (2020) Covid-19 pandemic, unemployment, and civil unrest: Underlying deep racial and socioeconomic divides. JAMA 324(3):227-228, DOI 10.1001/jama.2020.11132

13. Gilbert KL, Ray R, Siddiqi A, Shetty S, Baker EA, Elder K, Griffith DM (2016) Visible and invisible trends in black men's health: pitfalls and promises for addressing racial, ethnic, and gender inequities in health. Annual review of public health 37:295311

14. Halon Y (2020) Democrats using coronavirus 'as a tool to politicize things and scare people'. Fox News URL https://www.foxnews.com/media/ stephanie-grisham-callson-dems-to-stopusing-coronavirus-to-scare-public-forpoliticalpoints

15. Hutchinson B (2020) Alabama students throwing 'covid parties' to see who gets infected: Officials. ABC News URL https://abcnews.go.com/US/ alabama-students-throwing-covid-partiesinfected-officials/story?id=71552514

16. Jost JT, Glaser J, Kruglanski AW, Sulloway FJ (2003) Political conservatism as motivated social cognition. Psychological bulletin 129(3):339
17. Laditka JN, Laditka SB (2016) Unemployment, disability and life expectancy in the united states: A life course study. Disability and Health Journal 9:46-53, DOI 10.1016/j.dhjo.2015.08.003

18. Laurencin CT, McClinton A (2020) The covid-19 pandemic: a call to action to identify and address racial and ethnic disparities. Journal of Racial and Ethnic Health Disparities pp 1-5

19. Louis-Jean J, Cenat K, Njoku CV, Angelo J, Sanon D (2020) Coronavirus (covid-19) and racial disparities: a perspective analysis. Journal of racial and ethnic health disparities pp 1-7

20. Lumley T (2010) Complex Surveys: A Guide to Analysis Using R: A Guide to Analysis Using R. John Wiley and Sons

21. McLean SL, Foreman SD, Hoffman DR, Larimer CW, Scala DJ, Damore DF, Gill RD, Trende S, Preuhs RR, Provizer N, et al. (2018) Presidential Swing States. Rowman \& Littlefield

22. Michigangov (2020) Cases by demographic characteristics. Michigangov URL https: //www . michigan. gov/coronavirus/0, 9753, 7406-98163_98173---, 00.html

23. Millett GA, Jones AT, Benkeser D, Baral S, Mercer L, Beyrer C, Honermann B, Lankiewicz E, Mena L, Crowley JS, et al. (2020) Assessing differential impacts of covid-19 on black communities. Annals of Epidemiology

24. Morales DX, Morales SA, Beltran TF (2020) Racial/ethnic disparities in household food insecurity during the covid-19 pandemic: a nationally representative study. Journal of Racial and Ethnic Health Disparities pp 1-15

25. Nail PR, McGregor I (2009) Conservative shift among liberals and conservatives following 9/11/01. Social Justice Research 22(2-3):231-240

26. Neal ZP (2020) A sign of the times? weak and strong polarization in the us congress, 1973-2016. Social Networks 60:103-112

27. Pedulla DS (2018) How race and unemployment shape labor market opportunities: Additive, amplified, or muted effects? Social Forces 96(4):14771506, DOI 10.1093/sf/soy002

28. Phillips N, Park IW, Robinson JR, Jones HP (2020) The perfect storm: Covid-19 health disparities in us blacks. Journal of racial and ethnic health disparities pp 1-8

29. Renelus BD, Khoury NC, Chandrasekaran K, Bekele E, Briggs WM, Ivanov A, Mohanty SR, Jamorabo DS (2020) Racial disparities in covid19 hospitalization and in-hospital mortality at the height of the new york city pandemic. Journal of racial and ethnic health disparities pp 1-7 
30. Santiago CD, Wadsworth ME, Stump J (2011) Socioeconomic status, neighborhood disadvantage, and poverty-related stress: Prospective effects on psychological syndromes among diverse lowincome families. Journal of Economic Psychology $32(2): 218-230$

31. Tull MT, Edmonds KA, Scamaldo K, Richmond JR, Rose JP, Gratz KL (2020) Psychological outcomes associated with stay-at-home orders and the perceived impact of covid-19 on daily life. Psychiatry research p 113098

32. US Bureau of Labor Statistics (2020) Civilian unemployment rate. US Bureau of Labor Statistics URL https://www.bls.gov/ charts/employment-situation/civilianunemployment-rate.htm

33. US Census Bureau (2020) Quick facts: Michigan. US Census Bureau URL https://www.census. gov/quickfacts/MI?

34. Whitehead M (1991) The concepts and principles of equity and health. Health promotion international 6(3):217-228

35. Winship C, Radbill L (1994) Sampling weights and regression analysis. Sociological Methods \& Research 23(2):230-257 